\title{
An Overview of Buckling and Imperfection of Cone-Cylinder Transition under Various Loading Condition
}

\author{
O. Ifayefunmi* (D), M.S. Ismail ${ }^{b, c}$
}

aFaculty of Mechanical and Manufacturing Engineering Technology, Universiti Teknikal Malaysia Melaka, Malacca, Malaysia. Email: olawale@utem.edu.my

${ }^{b}$ Faculty of Mechanical Engineering, Universiti Teknikal Malaysia Melaka, Malacca, Malaysia. Email: mohdshahromismail@gmail.com 'Bahagian Kompetensi dan Peningkatan Kerjaya, Jabatan Pendidikan Politeknik dan Kolej Komuniti

* Corresponding author

https://doi.org/10.1590/1679-78256197

\begin{abstract}
The current paper presents a brief survey of literature relevant to buckling of cone-cylinder intersection under different loads such as (i) internal pressure, (ii) external pressure, and (iii) axial compression. The paper explores the up-to-date knowledge on the buckling of cone-cylinder intersection and highlights the areas of gap in knowledge. This is aimed at contributing to better understanding of the relevant issues such as the influence of different types of imperfections in updating the current design guideline that is found to be vital in industrial practice. The review is thematically divided into: (i) the methods adopted in the past work (i.e., how the data were obtained, type of material used, type of design with/without reinforcement), (ii) the highlight and importance of past findings, (iii) the sensitivity to imperfection and its design implications and (iv) the current design recommendation and guidelines. Finally, the current paper provides a brief state-ofthe-art and presents an update of related works for the future establishment of shells design guidelines.
\end{abstract}

\section{Keywords}

Cone-cylinder intersection, shell buckling, initial geometric imperfection, various loading condition

\section{Graphical Abstract}

A review of perfect and imperfect cone-cylinder structures subjected to:

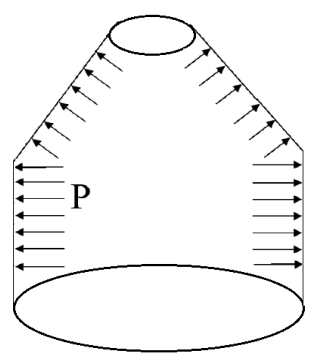

(a)

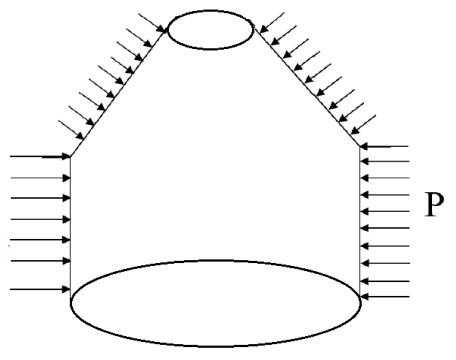

(b)

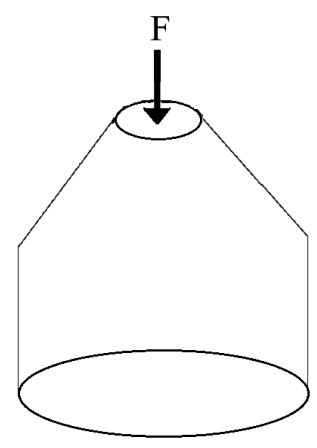

(c) 


\section{INTRODUCTION}

Cylinders with different closure at their ends by revolving shells (e.g. hemispheres, cones, etc.) are used in many engineering industries. They can be seen, for instance, in submersibles, missiles, reducer and silo and nuclear industries. The intersection is notably a simple weld-joint. In designing these cylinder/end closure combinations, it becomes necessary to take into account the structural capability in resisting the buckling occurrences caused by the excessive load during operation which can be catastrophic. Shell buckling is a common event in the industrial field and continuously attracts numbers of engineers/designers in finding the appropriate solution. The collapsed of Regent Street water tower in New Brunswick, Canada (Figure 1) is a typical example of structural failure caused by the occurrence of excessive compressive stress around the region of the cylinder-cone junction (Dawe et al., 1993). It was reported that the combination of material deficiency, design error and construction problems initiated the structural collapse. A few years later, a sudden burst of 16 years old corn silo (Figure 2 (a)) was reported by (Dogangun et al., 2009; Piskoty et al., 2005). Eventually, (Piskoty et al., 2005) explained that the main reason for the corn silo failure is due to the overloading condition around the corroded area.

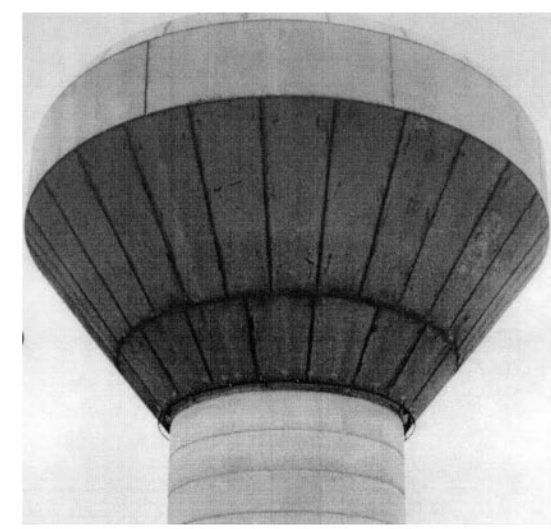

(a)

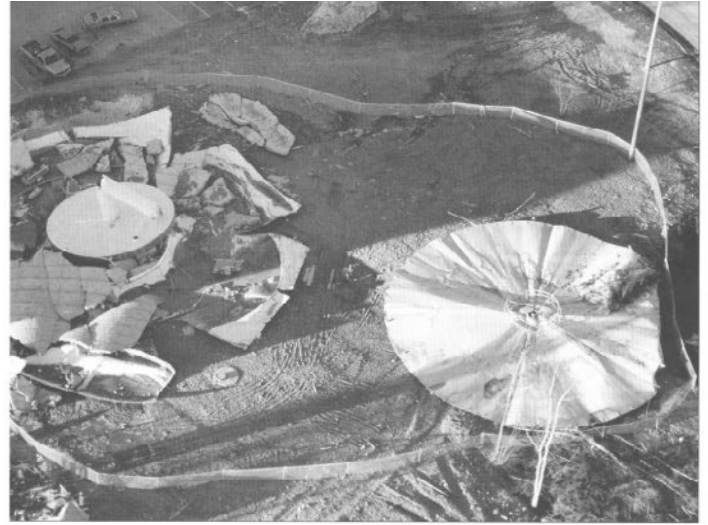

(b)

Figure 1. The water tower (i.e., elevated conical tank) located at Fredericton, New Brunswick, Canada (Figure 1a) and its collapsed (Dawe et al., 1993) (Figure 1b).

Recently in Poland, a corrugated stiffened silo designed according to the standard Eurocode guideline has intensely buckled along with its vertical columns as pointed by an arrow in Figure 2 (b). Thorough investigations have been conducted by means of comparing the Eurocode 3 guideline with nonlinear finite element (FE) analyses (Iwicki et al., 2015, 2011; Rejowski and Iwicki, 2016). It was later discovered that the silo design load was conservative as compared to the FE results. Iwicki et al. (2011) observed that the buckling strength of the columns was 2 - 4 times smaller than the allowable recommendation by Eurocode 3 . The overall investigations conclude that the initial imperfections in the form of eigenmode together with material non-linearity were the most detrimental for the silo thus resulting to inconsistent estimation of buckling load (20-55\% decrease of buckling strength).

Galletly (1988) reviewed several cases of failed vessels that occurred in the industry. Two (2) main loads were found to be largely responsible, which are: (a) axial compression and (b) external pressure. In addition, the influence of initial geometric imperfection associated with shells failure are comprehensively discussed. From his review, a number of recommendations were proposed in order to prevent structural failure, they are: (i) an experimentally validated design guideline that covers the wide range of buckling problems is necessary, (ii) the use of lower-bound experimental design curves is vital since the knowledge associate with the magnitude and distribution of initial geometric imperfection is very limited, (iii) for a near-perfect manufactured shell (e.g. machined) the use of lower-bound curves is unreasonable, and (iv) a random initial geometric imperfection is rather appropriate for the mass-production type of shells.

The shells failure pattern can be associated with its thickness, where: (i) thicker shell might result to axisymmetric or asymmetric buckling pattern (Ifayefunmi, 2015a; Ifayefunmi and Błachut, 2013), although (ii) thin shell buckles in the form of chessboard pattern (Kobayashi and Mihara, 2010; Krasovsky and Kostyrko, 2007). In 1996, Hayes (1996) comprehensively reviewed the cases of six pressure vessels failures. From his review, the root causes of the pressure vessels failure can be attributed to (i) sudden collapse of the pressure vessel due to shock loading, and (ii) the influence of residual stresses in the pressure vessel resulting from insufficient heat treatment process during stress relieving of the vessels. The failure cases discussed above highlight the practicality of the present design codes recommendations in dealing with structural buckling. In practice, the structural design is restricted to simple isotropic (stiffened or 
unstiffened) shells in the form of a cylinder or cone. From a design point of view, it seems to be appropriate to analyze the structural response individually. However, for the case of global behaviour, such as buckling (highly non-linear in terms of geometrical behaviour/deformation), a simplified idealization may not be valid and the complex shell needs to be considered.

The current paper explores the up-to-date knowledge on the buckling of cone-cylinder intersection and highlights the areas of a gap in knowledge. This is aimed at contributing to a better understanding of the relevant issues in updating the current design guideline that is found to be vital in industrial practice.

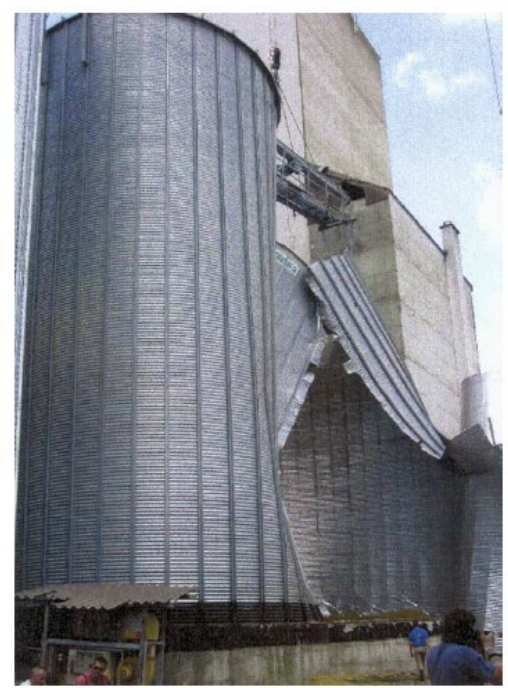

(a)

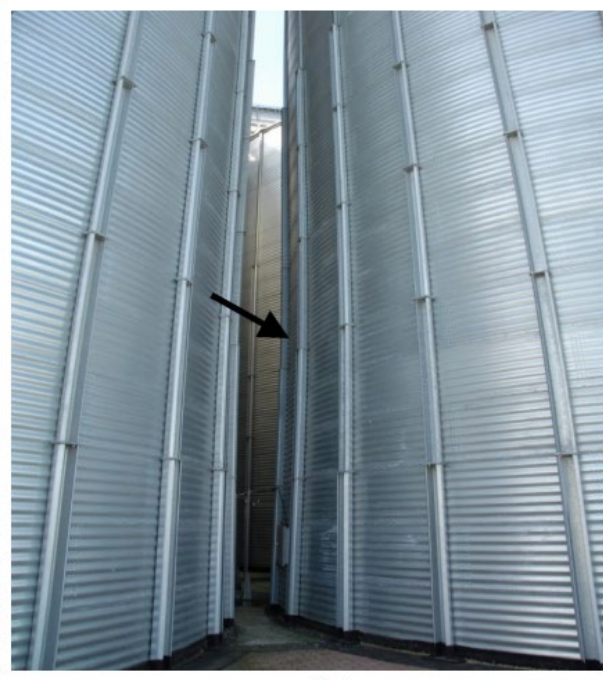

(b)

Figure 2. The failed accident of 16 years old silo (Piskoty et al., 2005) (Figure 2a) and the buckled of a vertical column of an empty silo that located at Poland (Iwicki et al., 2011) (Figure 2b).

\section{CONE-CYLINDER TRANSITION UNDER INTERNAL PRESSURE}

\subsection{Background and application}

Cone-cylinder shells are used extensively as pressure vessels in ocean engineering and chemical industries (Anwen, 1998). In general, the pressurize cone-cylinder shells failure pattern is categorized by 3 different modes, (i) axisymmetric failure, (ii) non-symmetric buckling and (iii) buckling of cone-cylinder intersection under localized circumferential compression. These types of failures are characterized by the wave occurrences around the shell's structure during or after buckling incident as reported in (Teng and Zhao, 2000). Under internal pressure, local stresses are found to be higher at the junction between the cone and the cylinder compared to the other part of the shell. The high local stresses mostly occur due to the presence of a slope discontinuity and susceptible to a plastic collapse (Teng, 1998). Special attention must be given to the presence of large hoop stresses at the junction that subsequently leads to failure, either axisymmetric collapse that describes the excessive inward axisymmetric or non-symmetric buckling deformation.

During operation, the internally pressurized silo (cone-cylinder junction) is expected to experience overpressures/bursting condition caused by their limited zones of the wall. Few of the works are reported in (Arnold et al., 1980; Jenike et al., 1973b, 1973a; Moore et al., 1984). The aforementioned statement confirms that cases involving burst pressure are seen in practice. For safety reason, Rotter (1986), suggested that the design of the entire wall must be able to sustain the highest pressure envelope. Although, it must be emphasized that most of the failure cases are attributed to the poor silos design rather than excessive pressures. Jenike et al. (1973b) highlighted that the overpressure condition is mostly associated with inward-bulging imperfection. Under internal pressure, several pressure vessel codes do not allow the use of cone-cylinder intersections without a toroidal knuckle when the cone half-apex angle is less than $30^{\circ}$ (AS1210, 1990; BS5500, 1988). The American Society of Mechanical Engineers (ASME) code (1986) has allowed such condition with additional reinforcement at the shells junction if the cone half-apex angle is greater than $40^{\circ}$.

\subsection{Past finding}

Hayakawa et al. (1977) carried out a study of simple cone-cone and cone-cylinder intersections under internal pressure via the finite element method. A thorough finite element investigation of the axisymmetric and non-symmetric 
failure of steel cone-cylinder intersections under uniform internal pressure are performed by Teng (1996a, 1995, 1994). Teng (1994) derived a simple design approximation to predict the shells failure strength based on the small-deflection elastic-plastic buckling loads (i.e. one-third stiffness loads and half stiffness loads) as the ultimate strengths. The useful effect of large deflections on failure strength was also developed. Subsequently, Teng (1995) established an accurate buckling strength equations for a non-symmetric bifurcation buckling problem. The non-symmetric bifurcation buckling results are presented in the range of shell geometries together with their approximate buckling load. Again, similar to axisymmetric failure analysis, an equation was developed to consider the effect of large deflections on failure strength.

A series of cone-cylinder intersections subjected to internal pressure with large geometrical defects have been tested (Gabriel, 1996). The tested shells appear to be unsuitable to evaluate due to the effect of fabrication imperfections in real structures. The development of an experimental facility for testing model steel silo transition junctions has been described by Teng et al. (2001). Several issues are covered including; (i) the precision of 3D measurement on geometric imperfections and deformed shapes using a laser-displacement meter, (ii) the fabrication quality of model junctions using thin steel sheets, and (iii) the loading method. A carefully conducted experimental on buckling of cone-cylinder intersections under internal pressure are described by Zhao and Teng (2001). The influence of initial imperfections with the aid of FE analysis was also reported.

The buckling of pressurized vessels using analytical and finite element method was reported in (Jones, 1994; Teng and Zhao, 2000). Teng and Zhao (2000) deployed research on the buckling of internally-pressurized cone-cylinder intersections based on the previous study conducted by (Jones, 1994). A detailed finite element study is reported to describe the failure of over-pressured vessels (2 cases) due to misoperation. Zhao and Teng (2003) developed a design proposal for practical use in the Eurocode format for internally pressurized steel cone-cylinder intersections. The design proposal was established based on the results from FE analyses and experimental data. A cylinder with a small cone end has been numerically analyzed by Yao et al. (2015). Niloufari et al. (2014) experimentally investigated the geometrical imperfection of twelve steel cone-cylinders intersection subjected to hydrostatic pressure.

Taylor and Polychroni (1983) examined the minimum weight conditions on concentrated ring reinforcement at the intersections between the equal thickness of vessels (i.e. conical and cylindrical parts) subjected to internal pressure using the limit analysis. Using a similar method i.e. limit analysis, Myler and Robinson (1985) reported some results on the intersecting conical pressure vessels. The necessity of reinforcement in the region of the junction is a focus of the study. A computer code was written for calculating the lower bound limit pressure. The stress distribution, plastic collapse behaviour and classical limit load analysis of steel silo transition junctions have been studied by Teng and Rotter (1991). An elastic-plastic large-deflection FE analysis is adopted to study the plastic collapse behaviour of this junction. The evaluation on the distribution of stresses, the effect of large deflections, the formation of a plastic collapse mechanism, and the collapse process of the shells are also reported. A major parametric study was conducted to examine the plastic collapse behaviour and strength of the complex transition steel silos junctions. Later on, an improved and straight forward equation was proposed for the use in design. Two failure modes for junctions between cylindrical and conical shells were discussed and analyzed in detail by Kalnins and Updike (1995).

Teng (1996a) investigated the elastic buckling and strength of cone-cylinder intersection with a ring, under localized circumferential compression. Equations to estimate the strength of cone-cylinder intersection were developed. Teng and Barbagallo (1997) analyzed the out-of-plane buckling strength of rings attached to cone-cylinder intersections under an elastic restrain. Again, a simple closed-form design formula was proposed and the results were compared with the FE shell buckling analysis. Teng and Chan (2001) developed a simple method for assessing the out-of-plane buckling strength of ring beams provided at the cone-cylinder intersection under internal pressure of an elevated storage silo and tank. Teng and Ma (1999) described the elastic buckling strength of ring-stiffened cone-cylinder intersections under internal pressure. Two main buckling modes were identified. Simple expressions were proposed which relate the number of circumferential buckling waves to the geometrical parameters of the intersection.

Teng (1998) described an effective area method to predicted the collapse strength of complex shell intersections formed by conical and cylindrical shell segments with or without a ring stiffener. The proposed formula is found to be satisfactory and suitable for codification purposes. Teng and Gabriel (1998) investigated the collapse behaviour and strength of the cone-cylinder intersections under internal pressure with locally increased wall thickness. Simple equations for the plastic limit loads were developed and the effect of the geometrical change was briefly discussed.

Zhao (2005) presented the experimental study of buckling behaviour of imperfect ring-stiffened cone-cylinder intersections under internal pressure. The given shells dimension is described to be $r=500 \mathrm{~mm}, t_{c y l i n d e r}=t_{c o n e}=t_{\text {ring }}=1$ $\mathrm{mm}, B=40^{\circ}$, and $B=20 \mathrm{~mm}$. For clarity, the terms $r, t, B$ and $B$ were designated for the ring-stiffened cone-cylinder radius, thickness, semi-vertex cone angle and height of the stiffener. The results from nonlinear bifurcation analysis using the perfect shape and nonlinear analysis using the measured imperfect shape were presented and compared against the 
experimental results. Khalili and Showkati (2012) presented results of an experiment and FE numerical estimation on buckling of T-ring stiffened cone-cylinder intersection subjected to internal pressure. A number of 3 specimens of identical steel cone-cylinder intersection with different ring-stiffened configuration were tested in the experimental part. The results of FE non-linear analysis and the experiment were compared against the design proposal established by Teng and Chan (2001).

An experimental and numerical investigation on cone-cylinder-skirt-ring junction subjected to internal pressure were presented by Zhao and Teng (2004a, 2004b). Zhao and Teng (2004a) recorded an amount of 5 tested cone-cylinderskirt-ring junction (specimens). Steel sheets with a thickness of ( $1 \mathrm{~mm}$ and $2 \mathrm{~mm}$ ) were used during the fabrication process. The geometric imperfections based on measurements and failure deformation of tested specimens were also included in the study. The used of (i) nonlinear bifurcation analysis, (ii) nonlinear analyses using measured imperfections, and (iii) nonlinear analyses using eigenmode-affine imperfections were fully deployed and analyzed as reported in (Zhao and Teng, 2004b).

\subsection{Summary of finding}

According to Teng (1994), the large deflections exhibit by a pressurized shallow cone with a thin intersection may establish a stable post-buckling response thus effectively strengthens the structure's intersection. Teng and Zhao (2000) re-examined the validity of the existing formulae for real vessels with geometric imperfections against the FE analysis and experimental results. The calculations demonstrated that the cone-cylinder intersection buckled first, followed by the buckling of the spherical partition. The analysis recorded a stable post-buckling path experienced by the shells. Due to a stable post-buckling path, the shells stiffness is reduced, instead of its loads carrying capacity. Again, the postbuckling path does not strongly depend on the magnitude of imperfections. The eigenmode imperfections provide good approximations with amplitudes of $w_{0} / t=0.01$ and $w_{0} / t=1$. Zhao and Teng (2001) indicated that the effect of initial imperfections was found to be very limited for cone-cylinder intersections under internal pressure. Again, the employed imperfect intersections through FE nonlinear analysis closely predicts the specimen's deformation caused by rupture failure at the weld line. For the case of imperfect stiffened cone-cylinder intersection subjected to internal pressure, Zhao and Teng (2004a, 2004b) reported that (i) geometric imperfections, (ii) effects of welding and (iii) the interaction between shells junction and cone/cylinder sections/compartments should be taken into account for a better numerical estimation against experimental. The measured imperfections produced an identical load-carrying capacity in comparison to imperfection model with amplitude $w_{0} / t=0.5-1$. The buckling deformation was found to be very minimal at cylinder and skirt in comparison to the ring section.

The establishment of ring reinforcement always improves the shells pressure strength. Taylor and Polychroni (1983) described the ring alone is enough to sustain the pressure with cone apex-angle below $40^{\circ}$. Nonetheless, additional reinforcement is required once the cone apex-angle is above $40^{\circ}$. Teng and Rotter (1991) reported a failure of steel silo complex transition junctions (ring-reinforcement) by a plastic collapse through large radial inward deformation with the unstable post-buckling response. According to Teng (1996a), the equivalent ring load approach has shown to be a reasonable and mostly conservative to the buckling load of a ring-stiffened cone-cylinder intersection. The application of rotational stiffness in the closed-form solution may reduce about $10 \%$ of buckling load for a similar shell (Teng and Barbagallo, 1997). Teng and Ma (1999) examined the ring-stiffened cone-cylinder intersections subject to internal pressure using linear and nonlinear FE analysis. Apparently, the numerical results showed that the effect of large deflections become significant when the ring cross-section is stocky. Two buckling modes were identified: (a) elastic buckling mode of failure for thin intersections, and (b) the decreasing effect of elastic buckling mode for thicker intersection, where the material plasticity may take place. In fact, the elastic buckling mode failure can be seen by the material made of higher strength steel or aluminium. The measurement of displacement (i.e. ring section) is found to be beneficial to determine the buckling mode and buckling load of ring-stiffened cone-cylinder intersections under internal pressure (Zhao, 2005).

Teng and Chan (2001) deployed an equation to approximate the strength of shell reinforced with T-section ring beams. The equation was found to be satisfactory enough to estimate the shell under uniform and non-uniform load (i.e. internal pressure). In addition, the derived equation underestimates the buckling load in the amount of $18.6 \%$ and $21.4 \%$ against finite element analysis. On the other hand, the manipulation of (i) material properties, (ii) buckling mode and (iii) amplitude give a strong effect on the accuracy of numerical prediction on internally pressurized T-ring stiffened conecylinder (Khalili and Showkati, 2012).

Sleeve reinforcement is one of the other alternative approaches to increase the strength of cone-cylinder intersection. This approach can be achieved by the use of a thicker plate (i.e. effective area) in the region near the point of intersection. Effective area method is described for the use of complex intersections of cones and cylinders under 
uniform pressure and improved by including the local pressure effect. Teng (1998) reported the accuracy of the effective area method under the comparison with finite element results. However, the effect of local pressure must be appropriately taken into account, especially for moderately thick intersections. According to Teng and Gabriel (1998), the shell strength improved substantially by employing the approach.

\section{CONE - CYLINDER TRANSITION UNDER EXTERNAL PRESSURE}

\subsection{Background and application}

Cylindrical shells with conical ends under external pressure are commonly found in a number of applications such as submarine hulls, nuclear test chambers and pipelines. To properly design this type of shell with a combination of its load action, specific consideration must be given to the development of stresses that may lead to structural collapse and instability. For this case, shell sizing is not the direct answer to minimize the occurring stresses during buckling event, as the shell may catastrophically collapse at a stress level that is well below the material's yield strength.

In general, a combined cone and cylinder assembly subjected to external pressure may collapse in two different ways. The shell may possibly (a) collapse (locally) within the cylindrical or conical portions or (b) both cylindrical and conical parts collapse simultaneously. There are three possible modes of collapse that can be described here: (i) axisymmetric collapse, (ii) asymmetric collapse and (iii) general instability. The (i) axisymmetric collapse is described when the structure deforms in a folded shape that develops between the ends of the shell. The collapse formation may or may not extend around the complete shell edge. The (ii) Asymmetric collapse often referred to as lobar buckling or panel instability. The mode is characterized by inward-outward dents which form on the shell. Similar to the axisymmetric collapse, the dents may occur at different locations along with the shell and may or may not extend around the entire edge. The (iii) general instability which is characterized by an overall asymmetric collapse of the complete shell including the stiffeners if they are present.

\subsection{Past finding}

Wenk Jr. and Taylor (1953) is considered to be the first researchers to evaluate the buckling performance of externally pressurize cylinder with conical end closure. In their work, equilibrium equations were derived and useful to solve the conical and reinforced cone-cylinder intersection buckling problem. Manning (1969) continued the study through his numerical work in analyzing similar segmented structure assembly. His theoretical solution covers prediction of the elastic general instability collapse pressure of a perfectly circular stiffened or unstiffened steel cylindrical shell with conical ends. Furthermore, a number of 524 and 144 numerical tests were analyzed specifically for the unstiffened and stiffened cylindrical shells with conical end closure.

In the early 1970s, tremendous works have been done in investigating the buckling performance of externally pressurize cylindrical shells with conical end closure. Aylward et al. $(1975,1973)$ presented some experimental and numerical results of nearly perfect steel cone-cylinder intersection. Within the content of numerical analysis, BOSOR 3 , a finite-difference program was used to calculate the shells buckling pressure on the theoretical part of the paper. Galletly et al. (1974) carried out an experimental work on six (6) carefully machined cylinder-cone combination subjected to uniform external pressure. The specimens were made from an aluminium alloy (Hiduminium $66-\mathrm{HE}-15$ ) and all the specimens were stress relieved after. An accompanying numerical comparison computed by BOSOR 3 and 5 programs was presented in the paper. The test models were fabricated in the form of identical half-models with different semivertex angle $\left(\alpha=45^{\circ}, 60^{\circ}\right.$ and $\left.75^{\circ}\right)$ and length to diameter ratio $(L / D=0.5$ and 1$)$. Bushnell and Galletly (1974) discussed an extension of the numerical and experimental work presented in (Galletly et al., 1974). Identical shell geometry and material properties to that of (Galletly et al., 1974) were used. The test models were machined from solid billets of aluminium alloy and undergo a quenching heat treatment in order to minimize the distortion and the formation of residual stresses. Then the shells were then subjected to a detailed thickness and diameter pre-test measurements. The circularity of the vessels at different locations was also checked by using an out-of-roundness measuring instrument. The measured diameters of the shells were within $0.15 \%$ of tolerance deviation. Bushnell (1974), numerically analyzed a similar dimension of the cone-cylinder model focusing on $45^{\circ}$ of conical angle by means of Aluminum 2039.

Schmidt and Swadlo through ECCS (1998) presented the numerical and experimental investigation of a combined steel cylinder and cone assemblies subjected to external pressure. The specimens were made from mild unalloyed steel St12 (Material-No.1.0330). Six (6) cylinder-cone assemblies with a configuration of $R / t=450$ and a thickness of $0.5 \mathrm{~mm}$ were tested to uniform external pressure. Besides that, numerical analysis was adopted to support the experimental work. The numerical analysis was presented according to the ECCS (1988a) guideline which consists of (i) linear analysis 
(LA), (ii) geometrical nonlinear analysis (GNA) and (iii) geometrical material nonlinear analysis (GMNA). In more recent, Ismail et al. (2020b, 2020a, 2018) carried out a numerical investigation into cone-cylinder transition subjected to external pressure by revisiting the work conducted by (Galletly et al., 1974). The study examined the buckling sensitivity of conecylinder intersection and the role of additional stiffener reinforcement at each section (cone/intersection/cylinder) subjected to external pressure. Three different stiffener locations are analyzed, they are (i) cone-cylinder junction, (ii) cone mid-section, and (iii) cylinder mid-section. Moreover, internal and external ring stiffeners are used in the study. A simple formula has been proposed that could reasonably be used to estimate the buckling of externally pressurized cone-cylinder shell transition under Geometrical and Materially Non-linear Analysis (GMNA) and Geometrical and Materially Non-linear Imperfection Analysis (GMNIA) cases with good correlation observed.

\subsection{Summary of finding}

Manning (1969) described that cone at the end of a cylindrical shell has a major influence on the overall shell buckling behaviour and collapse pressure. Through numerical analysis, he indicated a significant change in collapse pressure before the cone preceded to the $17^{\circ}$ angle. However, once the cone preceded the $17^{\circ}$ cone angle, the collapse pressure went slightly stable. This behaviour was found consistent for the case of R/t =84, 125 and 160 except for smaller $\mathrm{R} / \mathrm{t}=34$. For that reason, the stiffening/elastic effect of the cones becomes significantly less for large cone angles. Since stable/consistent buckling load is estimated for a larger cone angle, it may suggest that the required additional stiffener reinforcement seemed to be insignificant. Galletly et al. (1974) reported that the obtained experimental and numerical buckling pressures were in a very good agreement ( $2 \%-5 \%)$. The maximum discrepancies were found to be in the range of $2.4 \%-2.5 \%$ for Model 3 and Model 4 individually. It is evident that experimental data slightly overestimated the numerical results by $2 \%$. The specimen wall thickness and the value of elasticity were then checked and recalibrated again. Later on, it was found that the wall thickness of the specimens was inconsistent and deviated in the range of $1 \%$ $(0.0254 \mathrm{~mm})$. The value of material property (Hiduminium 48 ) was also deviated by $3 \%$ from its initial reading. In addition, the numerical results from BOSOR 3 showed that all of the tested shells behaved in an axisymmetric mode in the prebuckling event.

The study on combined steel cone and cylinder with various configurations subjected to external pressure were reported in (ECCS, 1998). It is evident that the numerical results overestimated the experiment. For example, the (i) cone-cone combination yielded to be $5 \%-12 \%$ and combination of (ii) three (3) sections (i.e. cylinder-conecylinder) amount of $52 \%-66 \%$. The failure mode was discovered to be a non-axisymmetric buckling for $\mathrm{R} / \mathrm{t}>150$. Again, the use of cylinder imperfection factor $\alpha$ for external pressure yield to a conservative estimation of buckling pressure.

For the case of stiffened cone-cylinder, a drastic drop of collapse pressure was recorded once the cone angle reached a certain amount of value for the case of different size of ring-stiffener (Manning, 1969). Furthermore, once the shell (i.e. cone angle) surpassed the drop of buckling pressure, a stable pressure load was then recorded although the cones angle was continuously increased. The value of cone angles was presented for $R / t=84: A_{f}=12.9032 \mathrm{~mm}^{2}\left(\beta=20^{\circ}\right)$, $A_{f}=32.258 \mathrm{~mm}^{2}\left(\beta=37^{\circ}\right)$ and $A_{f}=6212 \mathrm{~mm}^{2}\left(\beta=17^{\circ}\right)$. Again, it may suggest that the ring-stiffeners may be inappropriate for the larger cone angle mentioned above. Ismail et al. (2020b, 2020a, 2018) reported that under external pressure, the (i) shell with stiffened intersection appeared more prominent in resisting buckling through nonlinear analysis. Although in bifurcation study, (ii) stiffened the cone part was more noticeable in producing a stronger shell. In addition, internally stiffened (iii) the cone-cylinder intersection produces a much stronger shell compared to the external one. A few of initial geometric imperfections such as eigenmode imperfection and Single Load Indentation (SLI) imperfections were carried out in the analysis. As expected, the buckling strength of cone-cylinder shells was strongly affected by initial geometric imperfection and the reduction in buckling strength was seen to be strongly dependent on the choice and location of imperfection. A simple formula has been proposed for the case of externally pressurized cone-cylinder shell transition under Geometrical and Materially Non-linear Analysis (GMNA) and Geometrical and Materially Non-linear Imperfection Analysis (GMNIA).

\section{CONE - CYLINDER TRANSITION UNDER AXIAL COMPRESSION}

\subsection{Background and application}

Shell combinations such as cylinder with conical end closure are commonly used in many engineering industries. This may be related to aesthetical design and cost reduction factor either in fabrication and operational processes. The joining between two different cylinder diameters can be accomplished by having an insertion of 
cone section as a transition medium. During service, cone-cylinder transition/intersection shell may expose to extreme load in the form of external pressure, axial compression or combination of both. With this kind of load, the main concern must be emphasizing towards shells structural integrity, instability and safety. Failure to accommodate the load will result in a structure prone to buckling. Schmidt (2018), stated that different treatment is required once a buckle commenced on a cone-cylinder intersection as it is not an individual structural problem (i.e. cone or cylinder).

\subsection{Past finding}

The buckling of axially compressed steel cylinder-cone-cylinder interaction was first examined by Knoedel (1991). His work was purely numerical and focused on the elastic buckling of the assemblies under axial compression. Schmidt (2000); Schmidt and Krysik (1991); Schmidt and Swadlo, 1997) carried out an extensive investigation on the buckling of cylinder-cone-cylinder intersection under axial compression using numerical and experimental approaches. The membrane theory is also used to support the numerical and experimental results. Eighteen (18) steel shells of different geometrical combination between cone and cylinder were tested. The specimens were made from mild unalloyed steel St12 (Material-No.1.0330). Two different thicknesses were used $(0.5 \mathrm{~mm}$ and $1 \mathrm{~mm}$ ) with maximum and minimum diameters set to $450 \mathrm{~mm}$ and $159 \mathrm{~mm}$ respectively. From their results, a conservative design approach was recommended which was adopted in ECCS guideline: part C (ECCS, 1998). The numerical analysis was also adopted to support experimental work. The numerical analysis was presented according to the ECCS (1988a) guideline which consists of (i) linear analysis (LA), (ii) geometrical nonlinear analysis (GNA) and (iii) geometrical material nonlinear analysis (GMNA). In recent years, Mahdi et al. (2002) reported the crushing behaviour of composite cone-cylinder-cone shell and its performance in energy absorption.

\subsection{Summary of finding}

Schmidt $(2018,2000)$ identified a significant difference in the buckling mode for the case of axially compressed steel cylinder-cone-cylinder. In fact, the load-carrying-behaviour and the failure mode of cylinder-cone-cylinder transition are reasonably complex under axial load tests. For example, it is evident that the buckling mode shape was switched from the small area junction under linear analysis (LA) to the large area junction via geometrical nonlinear analysis (GNA) (refer Figure $3(\mathrm{~b})-(\mathrm{c}))$. Although both analyses are under the bifurcation level (ECCS, 2008). From the experiment, it was observed that specimen (ZKZ-XV10) experienced a local bending that triggers in accidental behaviour taking place at the small portion of the large junction area and the cone section (refer Figure 3 (a)). Both numerical analyses (i.e. bifurcation or nonlinear) failed to predict the pattern of buckling mode produced by the specimen. Moreover, for the case of $1 \mathrm{~mm}$ thickness, the numerical results (GMNA) underestimated the experiment buckling load. This can be seen for the case of (i) cone-cone combination $14 \%-26 \%$ and (ii) cone-cylinder-cone (i.e. three (3) shells section) to be around $16 \%-20 \%$. Nonetheless for the case of $0.5 \mathrm{~mm}$ thickness, the differences are estimated to be (i) cone-cone combination (14\% - 19\%) and (ii) cone-cylinder-cone (i.e. three (3) shells section) to be around 3\% - 18\%. In contrast, only specimen KZK-XX50 was found to overestimate the experimental buckling load by $4 \%$.

As reported in ECCS (1998), under axial compression, the steel cylinder-cone-cylinder transition with $20^{\circ}<\beta<40^{\circ}$ and $\mathrm{R} / \mathrm{t}<200$ failed by axisymmetric buckling (interactive yielding) at the shells junction. The influence of imperfection is reported to be insignificant for this type of failure mode. However, for $R / t>200$, the shell is failed predominated by buckling in the form of non-axisymmetric local yielding at the junction. The influence of imperfection was also examined by adopting the elastic imperfection reduction factor, $\alpha$ for meridional compression as specified in the ECCS (2008) recommendation into the perfect shells buckling load (GNMA). The shells buckling loads were later discovered to be conservative. Since the tested specimens experience a minimal geometrical imperfect tolerance, the calculated imperfection is most likely inappropriate. Nonetheless, if the worst-case scenario is considered, then the maximum reduction load of the imperfect shell is relatively critical (Błachut et al., 2013).

Surprisingly not much study has been done since 1998. However, it must be outlined that few questions can be addressed here, including: (i) the amount of imperfection magnitude and its influence on shell load carrying capacity and (ii) the suitable imperfection pattern/formation (i.e. size, shape and area/location) for the particular shell (i.e. conecylinder-cone sections). This is appropriate for cylinder-cone-cylinder assembly, as the structure is assembled with different shells configuration (i.e. cone/cylinder). To conclude, the influence of imperfection on structural buckling load is assumed to be complex for this type of shell assembly. 


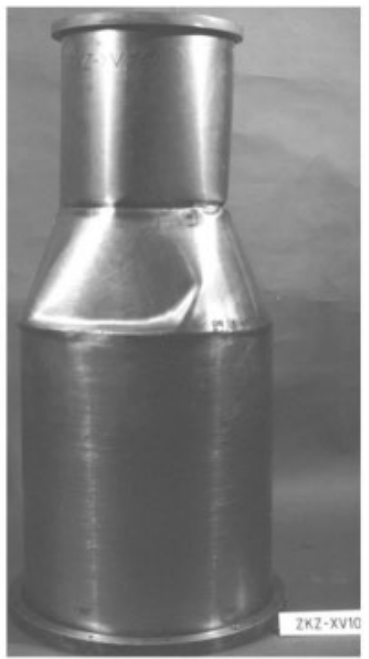

(a)

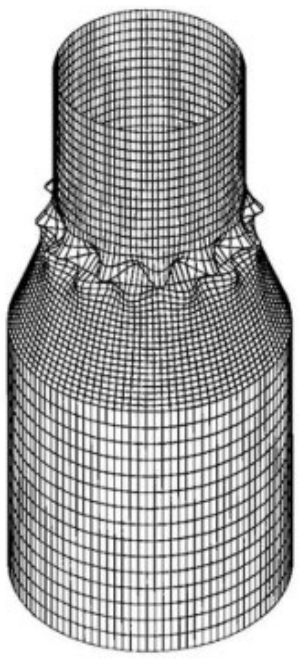

(b)

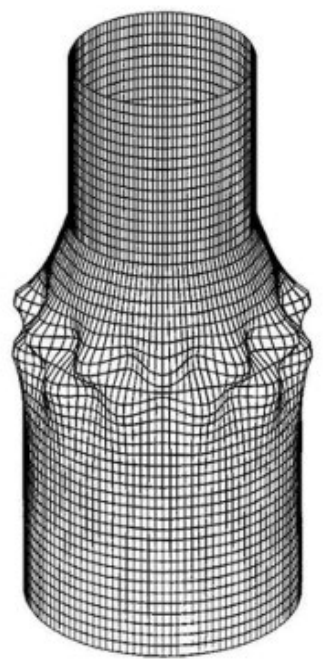

(c)

Figure 3. Specimen ZKZ-XV10, after testing (Figure 3a), LBA buckling mode (Figure 3b) and GNA buckling mode (Schmidt, 2018) (Figure 3c).

\section{SHELLS IMPERFECTION AND ITS DESIGN IMPLICATION}

Initial geometric imperfection is considered to be a challenging scenario the engineer/designer may expect, as it possibly will reduce the buckling strength of the shell structures. Questions on how it has been defined, positioned, maximum amplitude, worst shape etc. allow the designer to plan for the worst possible scenario such as unexpected catastrophic structural failure (Błachut, 2014). Typically, the shell buckling load is difficult to calculate and relatively gives large differences between experimental and theoretical estimations. This condition is associated with the presence of imperfection in real structures. In detail, the structure imperfection can be divided into three categories: (i) geometrical (ii) material and (iii) load-boundary condition prior to buckling event. Firstly, the geometrical imperfection relates to the corresponding miss-shaped, dimension, out-of-circularity and geometrical structures (dent, corroded, thinning). Secondly, the differences of material factors in isotropic material can be described through their properties such as elastic modulus, yield properties and strain-rate. In the view of material complexity, composite material by far would present influence in material nonlinearity by considering a number of factors such as fibre-angle misalignment, local ply-gaps and stacking sequence that bring a strong effect on structural imperfection. Lastly, the load-boundary condition continuously brings a strong effect on imperfection. This is illustrated during the buckling event, where the real buckling boundary condition is hard to quantify. It should take into account that during the compression event, the direction of the compressive load is not always perpendicular to the cylinder itself. Moreover, the corresponding event leads to unevenness in load distribution along the cylinder circumferential whereas the bending effect may take place in the whole buckling process.

Few examples of imperfection implication in designing the shell structure are discussed here. For convenience, the discussed shells are divided by different categories corresponding to their applied industries and dominant loading condition. In particular, the oil and gas or underwater exploration industries currently are being very active in sending the submersible vessel to the deepest zone undersea (Błachut, 2015a; Islam et al., 2012a, 2012b) with deepest dived been reached by Jiaolong vessel rated at $7 \mathrm{~km}$ depth (Pan et al., 2012). Usually, the pressure hull can be designed in many forms that depend on its application. Some of the design can be in a combination of a cylinder with domed (Błachut, 2016, 2015a, 2014; Błachut and Magnucki, 2008), conical-end (Błachut and Ifayefunmi, 2014; Gotsulyak and Zhadrasinov, 1985; Reuss, 1975) closures or reinforced with ring-stiffened (Ross et al., 2010; Ross and Humphries, 1993; Ross and Little, 2007). Despite remarkable achievements been accomplished with regard to the technology progress, there are still several issues in designing a modern pressure hull. A laboratory scale of steel pressure hull subjected to external hydrostatic pressure with consideration of structural imperfection has been tested by (Little et al., 2008; Ross et al., 2010, 2007, 2005; Ross and Little, 2007). Nonetheless, some of their results described that BS5500 (1988) design code is too pessimistic for shell instability and too optimistic for general instability. Ross et al. (2010) proposed a straight-forward design chart in calculating the vessel's critical pressure. Meanwhile, twenty models of an identical configuration of real pressure hull (i.e. aluminium ring-stiffened cylinder) were studied by (MacKay et al., 2010; MacKay and van Keulen, 2013) 
experimentally. The experimental results indicate that the hull's collapse pressure reduces accordingly to the severity of initial imperfection. Graham (2007) analyzed the real submarine pressure hulls fabrication residual stresses and shape imperfections into his finite element analyses of steel ring-stiffened cylinder. The discrepancy of the obtained results is within 6\%, although the results accuracy is strongly dependent on the detailed measurements of the structural imperfection.

In the meantime, Jones (1994) reported two case studies of failed vessels/reactor under external pressure. The first case is concerned with the development of inward-bulge/dent around the jacketed vessel's wall. The inward dent is presumably due to the increased of oil pressure in the reactor's jacket that reached the critical pressure of the reactor tube. The tube's geometrical imperfections are also suspected to initiate the buckling incident as the actual collapse pressures are only $80 \%$ of theoretical calculation (Calladine, 1983). The second case describes the failure behaviour of steel oil-storage vessel and its spherical partition/cap under internal pressure. The failure scenario illustrated that the vent pipe is smaller than the filling hose thus created a load-controlled condition as it allowed the air to enter the tank much faster than it could escape. Similar to the first case, experimental results indicated that the actual collapse pressures of steel spherical partition are in the range of $20 \%-60 \%$ of the theoretical value. Teng and Zhao (2000) revisit the second case via numerical and experimental approaches. The spherical cap/partition is assumed to satisfy the imperfection tolerance outlined by the ECCS (1988b) regulation. The results demonstrated that the vessel (i.e. conecylinder intersection) is not too sensitive to the influence of geometrical imperfection under internal pressure. In addition, the post-buckling path of the failed vessel is found not too strongly depend on the magnitude of imperfection.

It is well known that most of aerospace/aircraft structures are generally designed in the form of thin-walled structures. Therefore, issues associated with buckling, instability and collapse constantly take place in the relevant design as its tendency prone to buckling. In practice, commercial aircraft or launch vehicle (especially fuel tank) involves with a lot of extreme loads in the form of (i) structural payload (i.e. compressive direction) and (ii) internal/external pressure. Therefore, investigation on characterizing the structural buckling behaviour is essential to guarantee its safety and assurances. In particular, with regard to the aerospace structures, prediction of knockdown factor, $\rho\left(F_{\text {collapse }} / F_{\text {bifurcation }}\right)$ remains highly dependent on the empirical guideline from NASA SP-8007 (1968) that uses the conservative lower bound curve. Furthermore, the guideline is mainly intended for isotropic materials, and less information corresponding to composite material is described. The approach mentioned in the guideline excessively led to conservative designs on estimating cylinder buckling load as highlighted by researchers (Arbocz and Starnes Jr, 2002; Hilburger et al., 2006; Hühne et al., 2008). In particular, Arbelo et al. (2014) reported the use of NASA SP-8007 (1968) in the design of the European Ariane-5 rocket launcher. Even though the rocket has an outstanding performance, the structural design seemed to be considered conservative, resulting in high costs in production and operation (Castro et al., 2014; Haynie and Hilburger, 2010). The EU project DESICOS was launched in 2012 and it was intended to propose a new design guideline for designing imperfection in composite launcher structures (Degenhardt et al., 2014).

Actual shell may exhibit imperfection either in structural or material form. For example, offshore structure exposed to initial imperfection during the fabrication stage or shell's exploitation, i.e. existence of permanent dent during installation (Ifayefunmi, 2015b). With the presence of initial geometry imperfections and exposure to the extreme loading condition during service, structural integrity becomes a major issue. Although a tremendous amount of studies has been conducted to evaluate the influence of structural imperfection on buckling performance of pressurizes shell/vessel, so far there are still not sufficient information and guideline available. Certainly, the design of a shell structure is also depending on the engineer/designer experience. A new efficient design approach is expected to come up with possibilities for reducing the design cost and structural weight.

Several techniques were developed in the past to estimate the actual shell load-carrying capacity. This is essential in order to minimize the influence of geometrical initial imperfection. The relevant techniques discussed are (i) deviation from perfect geometry, (ii) eigenmode imperfection, (iii) single perturbation load approach (SPLA), (iv) boundary condition and load eccentricities and ( $v$ ) residual stress and its imperfections.

\subsection{Deviation from perfect geometry}

Numbers of researchers have performed an extensive experimental program specifically in buckling of axially compressed composite cylinders (Bisagni, 2000; Chryssanthopoulos, 1995; Chryssanthopoulos et al., 1999; Elghazouli et al., 1998). Prior to their work, the measurement of the thickness variation has been carried out by using a grid patch across the cylinder surface. The procedure is demonstrated by initially glueing a patch of grid boxes across the cylinder circumferential together with mounted vernier micrometre attached on a specially-designed bracket. Then the initial imperfection is measured using an automated laser scanning system. The subsequent reference surface has been 
created by means of scanning the test article at three different heights of a cylinder and further evaluated. Next, the automated scanning system is used to measure the buckling modes.

Despite the quality and best possible outcomes is expected from the procedure, the technique still has some limitation in return. The technique required a combination set of instrumentations to capture the structural buckling behaviour, which is allegedly expensive. Apart from that, the instrument needs to be calibrated, maintain and update frequently to sustain the quality of the experimental outcomes.

\subsection{Eigenmode imperfection}

The linear buckling modeshape imperfection is one of the popular methods that is used to predict the structural buckling load. Researchers referred this method as eigenmode-affine imperfections by Schmidt (2000) or linearbifurcation mode imperfection by Hilburger et al. (2006). This approach is performed by introducing the imperfection by adopting the eigenmode shapes together with specific imperfection amplitude. The imperfection amplitude for this method is based on scaling factors with its unitary maximum amplitude. The response of the buckling load varies with the range of scaling factors applied. The prediction of the lower-bound buckling load can be determined by escalating the level of imperfection amplitude beyond the standard in order to capture the structural defect during the manufacturing process (Haynie et al., 2010). This approach is one of the earliest attempts to consider the worst geometric imperfection pattern for a shell structure and predicted its knockdown factors. Evidently, there are a number of researchers have made an effort on implementing this technique (Castro et al., 2013a, 2013b; Ismail et al., 2013; Orifici and Bisagni, 2013; Tafreshi, 2002).

However, the method manifests several limitations, although it offers a reasonably good buckling load prediction. This may reflect the formation of eigenmode shape that typically is not represented as a real imperfection shape. Eigenmode imperfection is not always to be the worst imperfection shape, as various numbers of modeshapes and imperfection amplitude are needed to estimate the structural failure. The eigenmode imperfection approach is widely used in the industry to analyze the imperfection sensitivity. However, in practice, most imperfections found in structures do not have this buckling mode.

\subsection{Single perturbation load approach}

The single perturbation load approach (SPLA) which was proposed by Hühne et al. (2008), is relatively a new method in addressing imperfection on shell structures. The method uses the influence of a single lateral load applied to the cylinder mid-section in order to simulate the worst-case and realistic geometrical imperfection. Idealistically, the aim of conducting this technique is to attain consistency of buckling load as the magnitude of lateral load increases. It is wellknown that the imperfection including both the amplitude and the shape has a detrimental effect on the buckling strength of shells structures regardless of its shape or geometry. It can be said that the main basis of structural imperfection is dependent on the quality of the manufacturing process. For engineering design, the actual imperfection shape is very hard to be controlled in the manufacturing process while the maximum amplitude can be measured and controlled. Therefore, the worst-case geometrical imperfection is assumed in the practical design. The single perturbation load approach (SPLA) was regarded as one of the best approaches to find the worst-case geometrical imperfection.

Currently, DESICOS (DESign guideline for Imperfection sensitive COmposite launcher Structures) project is underway to propose a new design guideline for designing imperfection in aerospace launcher structures by means of single perturbation approach (SPLA) (Degenhardt et al., 2014). A new efficient design approach is expected to be proposed with possibilities for reducing the design cost and structural weight. The contribution of undergoing project can be related to the knowledge and guideline updates.

Arbelo et al. (2013) reported several studies on estimating the cylinder knockdown factor using the SPLA method, with a variation of cylinder ratios and fibres ply angles. It was found that small perturbation loads caused a roughly linear reduction in buckling load up to a certain transition point signalling structures instability. With the preceded increment of perturbation loads cause only a very small reduction relative to the transition point. This transition point was then proposed as a design point, and shown to provide buckling predictions that were less conservative and more appropriate than NASA SP-8007 guidelines (Ismail et al., 2015).

To extend the application of the SPLA, Arbelo et al. (2014) and Hao et al. (2014) introduced multiple lateral loads along the cylinder circumference to demonstrate the worst kind of imperfection level. The test was carried out to describe and initiate the range of worst multiple perturbation load approach (WMPLA). As a result, the MPLA gives more conservative results than the SPLA and in some extreme cases leads to the knockdown factor more closely to NASA SP 8007 guideline. On the other hand, Castro et al. (2013b) and Haynie and Hilburger (2010) conducted a comparison study 
between eigenmode imperfection and SPLA imperfection techniques. Castro et al. (2013b) explained the constancy of localized dent due to perturbation load and its relationship with global cylinder buckling load.

Throughout its development, the SPLA received many positive reviews towards its direct approach. This is evidently linked to its less conservative knockdown factor compared to the eigenmode imperfection method. Furthermore, the SPLA technique is much better and physically meaningful as it can validate with the experimental test. In contrast to eigenmode-affine, the imperfection is merely based on amplitude and eigenmode shape. However, there is a slight limit to the technique, as it requires a lot of possible tests to deduce the knockdown factor.

Despite an excellent performance achieved by DESICOS by employing SPLA technique, most of the works are still dominantly subjected to unstiffened cylinder exampled by Castro et al. (2014), conical shells by Khakimova et al. (2014) and sandwich structures by Orifici and Bisagni (2013). Recently, there is still a lack of data and effective guideline reported for a stiffened cylinder in adopting the SPLA by any independent or governed institutions. A further update is encouraged to meet with a new design challenge that suited to current technology demand.

\subsection{Imperfect length, boundary condition and load eccentricities}

Most of the time in practice, the shells i.e. cylinder and conical segments are formed together as a load-bearing structure to resist buckling corresponding to their nature of the application. However, when the load is in a compressive manner, the interaction between shell segments becomes critical, as the segment-to-segment interaction would possibly complicate the nature of buckling further. This problem has been identified many years ago, yet far from being comprehensively solved or understood. In particular, there are numerous ways to connect the segmented shells, the most common is welding or transition rings. However, if the shells length is uneven, it most likely may affect the loadcarrying capacity, regardless of the connection techniques (i.e. welding). The uneven shell's length might create a gap between two segments when they are in contact. As soon as the axial compression load is applied, the shape, axial and circumferential gaps dimension will change accordingly thus resulting in uneven loading or localized plastic deformation. These local effects from the shell's imperfect end and connection may trigger asymmetric bifurcation buckling or collapse. Consequently, these possible failure modes may cause a limitation in structural design.

Błachut notably addressed the problem a few years back. In his initial work (Błachut, 2010), axially compressed mild steel cylinders with non-uniform axial length are computed numerically. The non-uniform cylinder length is designed with a sinusoidal shape along the compressed edge that acts as the initial geometric imperfection. The cylinders were tested between $165 \leq R / t \leq 1000$ of radius-to-thickness ratio together with constant length-to-radius ratio, $L / R=2.4$. The ratio of the axial amplitude of imperfections to the wall thickness is set to be, $0 \leq A / t \leq 6$. The numerical results are then benchmarked with the experiment results of axially-perfect aluminium cylinders. The differences between the numerical and experimental results were shown to be $10 \%$ for model no. 1 . The computed results also indicate that the imperfect length significantly reduce the cylinder load-carrying capacity up to five times smaller to the eigenmode-imperfection approach. In the following years, the previous finding is experimentally verified as reported in (Błachut, 2015b). By this time, 18 CNC-machined mild steel cylinders were tested with the first three had perfect length while the rest is fabricated by having a variable-length at one end. Besides that, the experimental study is also supported by means of numerical results.

Typically, the axially compressed shell is expected to be centred between the line of axial load and the shell midskin. However, under uncontrolled circumstances, the load may be accidentally shifted from the central axis and initiate the load eccentricity to the shell. The load eccentricity additionally has been shown to relatively influence the shell buckling load and considered as another class of imperfection. Literally, numerous works have been carried out to address the issue, with few examples discussed here for cylinders (Eglitis, 2011; Eglitis et al., 2009; Simitses et al., 1985; Stuhlman et al., 1966), for cone (Błachut and Stanier, 2012) and stiffened cylinder (Block, 1968; Singer and Rosen, 1976). Besides that, the non-uniform axial compression (Libai and Durban, 1977; Papadopoulos and Iglesis, 2007) and uneven support distribution (Guggenberger et al., 2000; Teng and Rotter, 1992) may effectively influence the shells buckling strength and act as imperfection.

During axial compression, the apparent shell buckles and followed by a predominant inward lateral deflection. Anyhow, commencing the load eccentric is thought to be a solution to stabilize the shell, as it will present the contrary outward pre-buckling deformation. Simitses et al. (1985) studied the effect of load eccentric for axially compressed cylindrical shells with two types of materials (i.e. isotropic and orthotropic). His findings somehow do not support the recommendation of stabilizing the shells over eccentric load. In addition, small eccentricities seemed to be insensitive to the cylinder shells buckling load. In contrast, for the very large eccentricities (positive direction), the stabilizing effect appeared to be prominent. Nonetheless, the finding is based on observation to support the earlier argument of the eccentric load's positive effect. The negative eccentricities, on the contrary, brought a small destabilizing effect. It 
concludes that the stabilizing effect of large eccentricities may be linked to the Poisson effect. This is explained as the load continues to apply; the cylindrical shells deflected outward when the Poisson effect takes place. Once it reached a maximum expansion (critical load), the shells are then deflected back to the inward motion until its collapse.

For the stiffened cylinder, many studies have been conducted in the early 1970s by the use of numerical or experimental techniques. The studies indicated that the discrepancies in buckling load (extending to 50\%) reflect for the case of (i) eccentricities in loading condition or (ii) stiffener configuration. In practice, these differences may give some effect in structural design.

\subsection{Residual stress and its imperfections}

In general, residual stresses generated from various manufacturing processes have been suspected to be the main cause of premature cracking and failure in mechanical parts and structures. In a practical sense, it is common to relieve the high thermal stress region through mechanical treatment, for example by peening, over-loading, etc. This few examples provide a more favourable initial stress distribution thus improving the structure resistance to fatigue and/or fast fracture. Faulkner (1977) broadly discussed the nature and distribution of locked-in-stresses during forming (i.e. hot and cold) that brought a strong implication in reducing the strength and stiffness of the perfect structure. Pircher and Bridge (2001a, 1998, 2001b) looked more detail into the role of circumferential weld depression that produces residual stress for the axially compressed thin-walled cylinder. Their overall results suggest that the circumferential tension zone near the weld line increases the buckling strength of the shells structure.

The effect of residual stress on plastic buckling of axially compressed cylindrical shells with patterned welds has been examined experimentally and numerically by Yu et al. (2012). Two cylinders were tested with a different type of welding pattern and initial geometric imperfection. The finding confirmed the role of geometric imperfection with large residual stress in reducing the cylinders load-bearing capacity, thus supported the earlier study by Lennon (2006). Lennon (2006) quantified the drop of shells strength caused by the residual stress between the welded zone of cylinder and stiffener can be reached as far as 25\%. Tvergaard and Needleman (2001) explored the effect of residual stresses on localized buckling mode in elastic-plastic cylindrical panels subjected to axial compression. They conclude that the distributed residual stress decreased the load much slower once it reached its peak accordingly to the rise of residual stress. In contrast, the post-peak load changes differently with large residual stress.

A thorough numerical study of cylindrical shells due to localized fabrication imperfection that associated with the consistent presence of the residual stress field has been presented by Holst et al. (1999). It was confirmed from the study that the resulting consistent residual stress field may have a significant effect on the buckling strength of the shell. In a year later, Lancaster et al. (2000) experimentally tested about 64 samples of axially compressed melinex cylinder with $R / t$ of 1800 . The experiment aimed to look into the effect of imperfection originated from the local initial stress. The upper and lower edges of the cylinder were clamped to end discs by means of circumferential belts that produce a little friction load. The outcome of the test deliberately shows a very little effect of imperfection sensitivity that reduced the peak load in an average of $12 \%$.

Gannon (2010) evaluated the collapse of submarine hull structure by the use of effective stress-strain curves that incorporate the effects of cold bending residual stress. Supported through the verification of explicit FE simulation, the effective stress-strain curves with cold-bending residual stress were found to be more accurate in predicting the collapse of the pressure hull. The effect of residual stresses on the ultimate strength of stiffened cylinders (submarine hull) under combined loads has been numerically and experimentally examined by Cerik and Cho (2013a, 2013b). Two types of action to produce residual stress namely (i) welding and (ii) cold-bending were considered in FE analysis. The (i) welding action was simulated by cooling down the adjacent to stiffener-shell joints elements to a certain temperature with the aim of reaching the realistic magnitudes of weld-shrinkage. While the (ii) cold-bending is taken from the shells generated stresses (elastic spring back) through the cold-rolled process that forms a cylinder.

The results also point out that the residual stress produced from the welding process yields a reduction of shells strength in the ranges of $3 \%$ to $9 \%$. Moreover, it may suggest that the residual stress produced from the welding action is more profound in weaken the shells rather than cold-bending. The results also confirmed the spacing between stiffeners may contribute to further weaken the shells as well.

\section{SOME COMMENTARY ON CURRENT DESIGN PRACTICE: GEOMETRICAL TOLERANCE AND LIMITATION (IMPERFECTION)}

In spite of extensive works that have been conducted over the decades, knowledge of shell buckling problems is still very limited. Numerous shells instability design criteria have been established since, yet it is still restricted to the 
simplified assumption of shells in general design (i.e. cylinder, cone and spherical) under uniform load action (axial compression, external or internal pressures, torsion, bending, thermal). Nevertheless, in real industrial application, a combination of the aforementioned loads of action and geometrical non-linearity is inevitable. In practice, the shell stability design guidelines covering various structures have been applied in diverse industries such as (i) offshore platform (America Petroleum Institute, 2000; American Bureau of Shipping, 2004), (ii) aerospace (Weingarten et al., 1968), ship structure (American Bureau of Shipping, 2004), (iil) pressure vessel (ASME Boiler and Pressure Vessel Code, 1986; BS5500, 1988) and (iv) general design code application for steel structure (ECCS, 1988a, 1988b, 1998; Eurocode 3, 2007; Eurocode 9, 2006). The limited understanding to the behaviour of shells instability can be related with two main contributing factors which are the structural buckling complexity and its sensitivity to the initial geometric imperfection throughout the fabrication process (Teng, 1996b). Certainly, neglecting these contributing factors in the theoretical calculation may consequence an overestimate of the actual shells strength. Figure 4 shows an example of a NASA SP8007 knockdown factor curve together with available test data (Friedrich and Schröder, 2016).

Table 1 demonstrates some examples of shell geometrical tolerance (imperfection) from selected design codes. Table 2, on the other hand, shows some examples of stiffened shell geometrical tolerance (imperfection) from selected design codes. The ECCS (1998) stringer based tolerance/limitation seems to suffice enough to encounter the shells bending stiffness for a small number of stiffeners. Nonetheless, the bending stiffness appears to be minimal for the shell with a lot of stiffeners. Thus, the unstiffened shell tolerance is much applicable for this case. On the other hand, prevention of local instability of stringer and ring stiffened is essential and their ratios of cross-section must sufficiently follow the given requirement of design codes.

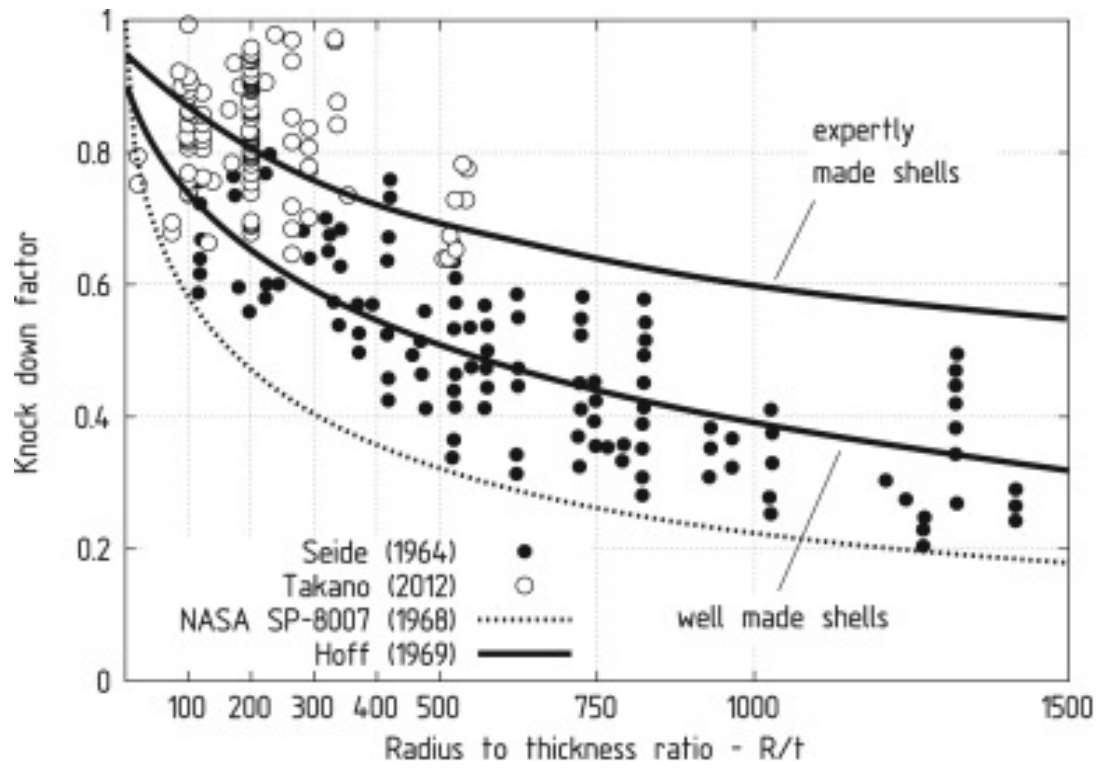

Figure 4. The curve of NASA SP-8007 together with available test data (Friedrich and Schröder, 2016).

Table 1. Shell geometrical tolerance from selected design codes.

\begin{tabular}{|c|c|}
\hline Codes & Imperfection tolerance \\
\hline ECCS (1998) & $w_{o}=0.01 l_{r}, l_{r}=4 \sqrt{r t}$ \\
\hline $\operatorname{DnV}(1995)$ & $w_{o}=\frac{0.05 l_{r}}{1+l_{r} / r}, l_{r}=4 \sqrt{r t}$ \\
\hline \multirow[t]{2}{*}{ EC3 and EC9 (2007; 2006) } & $w_{o}=U_{r \max } l_{g \theta, x}, l_{g \theta, \text { circumferential }}=2.3\left(l^{2} r t\right)^{0.25}$ \\
\hline & or $l_{\text {gx, axial compression }}=4 \sqrt{r t}$ \\
\hline API (2000) & $w_{o}=0.01 l_{r}, l_{r}=4 \sqrt{r t}$ \\
\hline
\end{tabular}


Table 2. Stiffened shells geometrical tolerance from selected design codes.

\begin{tabular}{ccc}
\hline \multirow{2}{*}{ Codes } & \multicolumn{2}{c}{ Imperfection tolerance } \\
\cline { 2 - 3 } & Ring-stiffened & Stringer-stiffened \\
\hline ECCS (1998) & $\bar{u}=0.01 l_{r}, l_{r}=4 \sqrt{r t_{s}}$ & $\bar{w}=0.0015 l_{g}, l_{g}=L$, for $A_{s} / b t \geq 0.06$ \\
& & $\bar{w}=0.01 l_{r}, l_{r}=4 \sqrt{r t}$, for $A_{s} / b t \leq 0.06$ \\
$\operatorname{DnV}(1995)$ & - & $\bar{w}=0.0015 l_{g}$, for $l_{g}=L_{s}$ \\
API (2000) & $\bar{w}=0.002 l_{r}, l_{r}=L_{r}$ & $\bar{w}=0.0015 l_{g}$, for $l_{g}=L_{f}$ \\
\hline
\end{tabular}

\section{CLOSURE}

The paper provides a critical review on the buckling and ultimate strength of cone-cylinder intersections. From the review, it can be seen that many theoretical, numerical and experimental studies have been carried out to provide a better guideline for designing the particular shell. In particular, it is widely reported that no efficient guidelines in designing the cone-cylinder intersection shells are available. It is evident that the imperfection pattern/formation (i.e. size, shape and area/location) and its magnitude play a vital role in estimating the shell load-carrying capacity. This seems to be appropriate for cylinder-cone-cylinder assembly since the structure is configured with more than different shells and junctions/intersections. In addition, the influence of imperfection is assumed to be complex for this type of structural assembly.

\section{ACKNOWLEDGEMENT}

The authors wish to acknowledge the financial assistance received from Universiti Teknikal Malaysia Melaka (UTeM) and the Ministry of Education Malaysia through Fundamental Research Grant Scheme FRGS/2018/FTKMP-CARE/F00386.

Author's Contributions: Conceptualization, O Ifayefunmi; Investigation, MS Ismail; Formal analysis, MS Ismail, O Ifayefunmi; Writing - original draft, MS Ismail, O Ifayefunmi; Visualization, MS Ismail, O Ifayefunmi; Writing - review \& editing, O Ifayefunmi, MS Ismail; Funding acquisition, O Ifayefunmi; Supervision, O Ifayefunmi.

Editor: Pablo Andrés Muñoz Rojas.

\section{REFERENCES}

America Petroleum Institute, 2000. Bulletin on Stability Design of Cylindrical Shells. Washington D.C.

American Bureau of Shipping, 2004. Buckling and Ultimate Strength Assessment for Offshore Structures. Houston, TX.

Anwen, W., 1998. Stresses and stability for the cone-cylinder shells with toroidal transition. International Journal of Pressure Vessels and Piping, 75, pp. 49-56.

Arbelo, M.A., Degenhardt, R., Castro, S.G.P., Zimmermann, R., 2014. Numerical characterization of imperfection sensitive composite structures. Composite Structures, 108, pp. 295-303.

Arbelo, M.A., Zimmermann, R., Castro, S.G.P., 2013. Comparison of new design guidelines for composite, in: Ninth International Conference on Composite Science and Technology. Sorrento, Italy, pp. 96-111.

Arbocz, J., Starnes Jr, J.H., 2002. Future directions and challenges in shell stability analysis. Thin-Walled Structures, 40, pp. 729-754.

Arnold, P.C., Mclean, A.G., Roberts, A.W., 1980. Bulk solids : storage, flow and handling. TUNRA Ltd, University of Newcastle, New South Wales, Australia.

AS1210, 1990. AS1210: SAA unfired pressure vessel code. Association of Standards - Australia, Sydney, Australia, Sydney, Australia. 
ASME Boiler and Pressure Vessel Code, 1986. Section III, division 1: rules for construction of pressure vessels, ASME Boiler and Pressure Vessel Code. American Society of Mechanical Engineers, New York.

Aylward, R.W., Galletly, G.D., Moffat, D.G., 1975. Buckling under external pressure of cylinders with toriconical or pierced torispherical ends: a comparison of experiment with theory. ARCHIVE: Journal of Mechanical Engineering Science 1959-1982 (Vols 1-23), 17, pp. 11-18.

Aylward, R.W., Galletly, G.D., Moffat, D.G., 1973. Some experimental/theoretical results on the buckling under external pressure of cylinders with various end closures, in: Proc. 2nd Int. SmiRt (Structural Mechanics in Reactor Technology Conference. West Berlin, Germany, pp. 1-6.

Bisagni, C., 2000. Numerical analysis and experimental correlation of composite shell buckling and post-buckling. Composites Part B: Engineering, 31, pp. 655-667.

Błachut, J., 2016. Buckling of composite domes with localised imperfections and subjected to external pressure. Composite Structures, 153, pp. 746-754.

Błachut, J., 2015a. Locally flattened or dented domes under external pressure. Thin-Walled Structures, 97, pp. 44-52.

Błachut, J., 2015b. Buckling of Cylinders With Imperfect Length. Journal of Pressure Vessel Technology, 137, pp. 1-7.

Błachut, J., 2014. Experimental Perspective on the Buckling of Pressure Vessel Components. Applied Mechanics Reviews, 66, pp. 1-24.

Błachut, J., 2010. Buckling of axially compressed cylinders with imperfect length. Computers and Structures, 88, pp. 365-374.

Błachut, J., Ifayefunmi, O., 2014. Toricones: Burst Pressures, in: In B.H.V. Topping, P. Iványi, (Editors), Proceedings of the Twelfth International Conference on Computational Structures Technology. Stirlingshire, UK, p. Paper 207.

Błachut, J., Magnucki, K., 2008. Strength, Stability, and Optimization of Pressure Vessels: Review of Selected Problems. Applied Mechanics Reviews, 61, pp. 060801-1.

Błachut, J., Muc, A., Rys, J., 2013. Buckling of Unstiffened Steel Cones Subjected to Axial Compression and External Pressure. Journal of Offshore Mechanics and Arctic Engineering, 135, pp. 1-9.

Błachut, J., Stanier, D., 2012. Elastic Buckling of Conical Shells under the Combined Loading of Axial Compression and External Pressure, in: Topping, B.H. (Ed.), Proceedings of the Eleventh International Conference on Computational Structures Technology. Civil-Comp Press, Stirlingshire, UK,

Block, D.L., 1968. Influence of discrete ring stiffeners and prebuckling deformation on the buckling of eccentrically stiffened orthotropic cylinders. NASA TN D-4283, Washington, D.C.

BS5500, 1988. BS5500: specification of unfired fusion welded pressure vessels. British Standards Institution, London, England.

Bushnell, D., 1974. Bifurcation buckling of shells of revolution including large deflections, plasticity and creep. International Journal of Solids and Structures, 10, pp. 1287-1305.

Bushnell, D., Galletly, G.D., 1974. Comparisons of test and theory for nonsymmetric elastic-plastic buckling of shells of revolution. International Journal of Solids and Structures, 10, pp. 1271-1286.

Calladine, C.R., 1983. Theory of shell structures. Cambridge University Press.

Castro, S.G.P., Zimmermann, R., Arbelo, M.A., Degenhardt, R., 2013a. The single perturbation load approach compared with linear buckling mode-shaped, geometric dimple and measured imperfections for the buckling of cylindrical shells. Thin Walled Structure, pp. 1-14.

Castro, S.G.P., Zimmermann, R., Arbelo, M.A., Degenhardt, R., 2013b. Exploring the constancy of the global buckling load after a critical geometric imperfection level in thin-walled cylindrical shells for less conservative knock-down factors. Thin-Walled Structures, 72, pp. 76-87.

Castro, S.G.P., Zimmermann, R., Arbelo, M.A., Khakimova, R., Hilburger, M.W., Degenhardt, R., 2014. Geometric imperfections and lower-bound methods used to calculate knock-down factors for axially compressed composite cylindrical shells. ThinWalled Structures, 74, pp. 118-132.

Cerik, B.C., Cho, S.R., 2013a. Numerical investigation on the ultimate strength of stiffened cylindrical shells considering residual stresses and shakedown. Journal of Marine Science and Technology (Japan), 18, pp. 524-534. 
Cerik, B.C., Cho, S.R., 2013b. Residual Strength of Damaged Stiffened Cylinders under Combined Axial Compression and Radial Pressure, in: Proceedings of the PRADS2013. Changwon City, Korea, pp. 1075-1082.

Chryssanthopoulos, M.K., 1995. Stochastic Imperfection Modelling in Shell Buckling Studies Stiffener depth. Thin-Walled Structures, 23, pp. 179-200.

Chryssanthopoulos, M.K., Elghazouli, A.Y., Esong, I.E., 1999. Compression tests on anti-symmetric two-ply GFRP cylinders. Composites Part B: Engineering, 30, pp. 335-350.

Dawe, J.L., Seah, C.K., Abdel-Zaher, A.K., 1993. Investigation of the Regent Street Water Tower Collapse. Management \& Operations, pp. 34-47.

Degenhardt, R., Castro, S.G.P., Arbelo, M.A., Zimmermann, R., Khakimova, R., Kling, A., 2014. Future structural stability design for composite space and airframe structures. Thin-Walled Structures, 81, pp. 29-38.

DnV, 1995. Buckling strength analysis. Det Norske Veritas AS, pp. 1-44.

Dogangun, A., Karaca, Z., Durmus, A., Sezen, H., 2009. Cause of Damage and Failures in Silo Structures. Journal of Performance of Constructed Facilities, 23, pp. 65-71.

ECCS, 2008. Buckling of steel shells european design recommendations. Buckling of Shells 5th Ed Brussels: European Convention for Constructional Steelwork,

ECCS, 1998. Enhancement of ECCS design recommendations and development of Eurocode 3 parts related to shells buckling. Buckling of Shells 5th Ed Brussels: European Convention for Constructional Steelwork,

ECCS, 1988a. ECCS Publication - Buckling of Steel Shells: European Recommendations.

ECCS, 1988b. Buckling of steel shells : European recommendations. Buckling of Shells 5th Ed Brussels: European Convention for Constructional Steelwork, pp. 384.

Eglitis, E., 2011. Dynamic buckling of composite shells. Riga Technical University, Riga, Unpublished Phd thesis.

Eglitis, E., Kalnins, K., Ozolins, O., 2009. Experimental and Numerical Study on Buckling of Axially Compressed Cylinders. Construction Science, 10, pp. 33-49.

Elghazouli, A.Y., Chryssanthopoulos, M.K., Spagnoli, A., 1998. Experimental response of glass-reinforced plastic cylinders under axial compression. Marine Structures, 11, pp. 347-371.

Eurocode 3, 2007. Eurocode 3 - Design of steel structures - Part 1-6: Strength and stability of shell structures.

Eurocode 9, 2006. Eurocode 9 - Design of aluminium structures - Part 1-5: Shell structures. European comitee for standardization, Brussels, Belgium.

Faulkner, D., 1977. Effects of residual stresses on the ductile strength of plane welded grillages and of ring stiffened cylinders. The Journal of Strain Analysis for Engineering Design, 12, pp. 130-139.

Friedrich, L., Schröder, K.-U., 2016. Discrepancy between boundary conditions and load introduction of full-scale built-in and sub-scale experimental shell structures of space launcher vehicles. Thin-Walled Structures, 98, pp. 403-415.

Gabriel, B., 1996. Behaviour and strength of plate-end and cone-end pressure vessels. Unpublished MEngSc Thesis, James Cook University.

Galletly, G.D., 1988. Buckling of pressure vessels. Science Progress, 72, pp. 371-405.

Galletly, G.D., Aylward, R.W., Bushnell, D., 1974. An experimental and theoretical investigation of elastic and elastic-plastic asymmetric buckling of cylinder-cone combinations subjected to uniform external pressure. Ingenieur-Archiv, 43, pp. 345-358.

Gannon, L., 2010. Prediction of the effects of cold bending on submarine pressure hull collapse. Technical Memorandum, DRDC Atlantic TM 2010-065.

Gotsulyak, E.A., Zhadrasinov, N.T., 1985. Stability of torispherical and toriconical vessel heads under internal pressure. Soviet Applied Mechanics, 21, pp. 40-45.

Graham, D., 2007. Predicting the collapse of externally pressurised ring-stiffened cylinders using finite element analysis. Marine Structures, 20, pp. 202-217. 
Guggenberger, W., Greiner, R., Rotter, J.M., 2000. Behaviour of locally-supported cylindrical shells: Unstiffened shells. Journal of Constructional Steel Research, 56, pp. 175-197.

Hao, P., Wang, B., Li, G., Meng, Z., Tian, K., Zeng, D., Tang, X., 2014. Worst Multiple Perturbation Load Approach of stiffened shells with and without cutouts for improved knockdown factors. Thin-Walled Structures, 82, pp. 321-330.

Hayakawa, T., Yoshida, T., Mii, T., 1977. Collapse Pressure for Small End of A Cone-Cylinder Junction Based on Elastic-Plastic Analysis, in: Proceedings, 3rd International Conference on Pressure Vessel Technology, Tokyo, Japan, pp. 149-156.

Hayes, B., 1996. Six case histories of pressure vessel failures. Engineering Failure Analysis, 3, pp. 157-170.

Haynie, W.T., Hilburger, M.W., 2010. Comparison of Methods to Predict Lower Bound Buckling Loads of Cylinders under Axial Compression. 51st AIAA/ASME/ASCE/AHS/ASC Structures, Structural Dynamics, and Materials Conference, pp. 1-22.

Haynie, W.T., Hilburger, M.W., Kriegesmann, B., 2010. Validation of Lower-Bound Estimates for Compression-Loaded Cylindrical Shells. 51st AIAA/ASME/ASCE/AHS/ASC Structures, Structural Dynamics, and Materials Conference, pp. 1-12.

Hilburger, M.W., Nemeth, M.P., Starnes, J.H., 2006. Shell Buckling Design Criteria Based on Manufacturing Imperfection Signatures. AlAA Journal, 44, pp. 654-663.

Holst, F.G., Rotter, J.M., Calladine, C.R., 1999. Imperfetion in cylindrical shells resulting from fabrication misfits. Journal of Engineering Mechanics, 125, pp. 410-418.

Hühne, C., Rolfes, R., Breitbach, E., Teßmer, J., 2008. Robust design of composite cylindrical shells under axial compression Simulation and validation. Thin-Walled Structures, 46, pp. 947-962.

Ifayefunmi, O., 2015a. Plastic buckling of axially compressed thick unstiffened steel cones. Ocean Engineering, 103, pp. 1-9.

Ifayefunmi, O., 2015b. Effect of prebuckling and edge support on the bifurcation buckling of torisphere, cylinder and cone. Journal of Engineering and Technology, 4, pp. 137-158.

Ifayefunmi, O., Błachut, J., 2013. Instabilities in imperfect thick cones subjected to axial compression and external pressure. Marine Structures, 33, pp. 297-307.

Islam, A.B.M.S., Jameel, M., Jumaat, M.Z., 2012a. Oil and gas energy potential at malaysian seabed and spar platform for deepwater installation. International Journal of Green Energy, 9, pp. 111-120.

Islam, A.B.M.S., Jameel, M., Jumaat, M.Z., Shirazi, S.M., Salman, F.A., 2012b. Review of offshore energy in Malaysia and floating Spar platform for sustainable exploration. Renewable and Sustainable Energy Reviews, 16, pp. 6268-6284.

Ismail, M.S., Baharudin, B.T.H.T., Talib, Z., Yahya, S.A., 2013. Improvement of Cylinder Buckling Knockdown Factor through Imperfection Sensitivity. Advanced Materials Research, 845, pp. 226-230.

Ismail, M.S., Ifayefunmi, O., Fadzullah, S.H.S.M., 2018. The role of stiffener in resisting buckling of externally pressurized conecylinder intersection, in: Proceedings of Mechanical Engineering Research Day. pp. 55-56.

Ismail, M.S., Ifayefunmi, O., Fadzullah, S.H.S.M., Johar, M., 2020a. Buckling of imperfect cone-cylinder transition subjected to external pressure. International Journal of Pressure Vessels and Piping, 187, pp. 104173.

Ismail, M.S., Ifayefunmi, O., Sheikh Md Fadzullah, S.H., 2020b. Buckling Analysis of Stiffened Cone-Cylinder Intersection Subjected to External Pressure. Key Engineering Materials, 833, pp. 223-227.

Ismail, M.S., Purbolaksono, J., Andriyana, A., Tan, C.J., Muhammad, N., Liew, H.L., 2015. The use of initial imperfection approach in design process and buckling failure evaluation of axially compressed composite cylindrical shells. Engineering Failure Analysis, 51, pp. 20-28.

Iwicki, P., Rejowski, K., Tejchman, J., 2015. Stability of cylindrical steel silos composed of corrugated sheets and columns based on FE analyses versus Eurocode 3 approach. Engineering Failure Analysis, 57, pp. 444-469.

Iwicki, P., Wójcik, M., Tejchman, J., 2011. Failure of cylindrical steel silos composed of corrugated sheets and columns and repair methods using a sensitivity analysis. Engineering Failure Analysis, 18, pp. 2064-2083.

Jenike, A.W.W., Johanson, J.R., Carson, J.W.W., 1973a. Bin Loads-Part 3: lass-Flow Bins. Journal of Engineering for Industry, 95, pp. 6-12.

Jenike, A.W.W., Johanson, J.R.R., Carson, J.W.W., 1973b. Bin Loads - Part 2 : Concepts. Journal of Engineering for Industry, 95, pp. 1-5. 
Jones, D.R.H., 1994. Buckling failures of pressurised vessels-two case studies. Engineering Failure Analysis, 1, pp. $155-167$.

Kalnins, A., Updike, D.P., 1995. Effect of Reinforcement on the Strength of Junctions Between Cylindrical and Conical Shells. Journal of Pressure Vessel Technology, 117, pp. 135-141.

Khakimova, R., Warren, C.J., Zimmermann, R., Castro, S.G.P., Arbelo, M.A., Degenhardt, R., 2014. The single perturbation load approach applied to imperfection sensitive conical composite structures. Thin-Walled Structures, 84, pp. 369-377.

Khalili, F., Showkati, H., 2012. T-ring stiffened cone cylinder intersection under internal pressure. Thin-Walled Structures, 54, pp. 54-64.

Knoedel, P., 1991. Cylinder-cone-cylinder intersections under axial compression. Buckling of Shell Structures, on Land, in the Sea and in the Air, London.

Kobayashi, T., Mihara, Y., 2010. Application of Abaqus for Practical Postbuckling Analyses of Cylindrical Shells under Axial Compression, in: 2010 SIMULIA Customer Conference. pp. 1-15.

Krasovsky, V., Kostyrko, V.V., 2007. Experimental studying of buckling of stringer cylindrical shells under axial compression. Thin-Walled Structures, 45, pp. 877-882.

Lancaster, E.R., Calladine, C.R., Palmer, S.C., 2000. Paradoxical buckling behaviour of a thin cylindrical shell under axial compression. International Journal of Solids and Structures, 42, pp. 843-865.

Lennon, R.F., 2006. The Effects of Cold Forming and Welding Residual Stress States on the Buckling Resistance of Orthogonally Stiffened Cylinders. Applied Mechanics and Materials, 5-6, pp. 509-518.

Libai, A., Durban, D., 1977. Buckling of Cylindrical Shells Subjected to Nonuniform Axial Loads. Journal of Applied Mechanics, 44, pp. 714-720.

Little, A.P.F., Ross, C.T.F., Short, D., Brown, G.X., 2008. Inelastic buckling of geometrically imperfect tubes under external hydrostatic pressure. Journal Of Ocean Technology, 3, pp. 75-90.

MacKay, J.R., van Keulen, F., 2013. The Sensitivity of Overall Collapse of Damaged Submarine Pressure Hulls to Material Strength. Journal of Offshore Mechanics and Arctic Engineering, 135, pp. 021403.

Mackay, J.R., Smith, M.J., van Keulen, F., Bosman, T.N., Pegg, N., 2010. Experimental investigation of the strength and stability of submarine pressure hulls with and without artificial corrosion damage. Marine Structures, 23, pp. 339-359.

Mahdi, E., Hamouda, A.M.S., Sahari, B.B., Khalid, Y.A., 2002. Crushing Behavior of Cone-Cylinder-Cone Composite System. Mechanics of Advanced Materials and Structures, 9, pp. 99-117.

Manning, S.D., 1969. General instability of a cylindrical shell with conical ends subject to uniform external pressure. Texas Technological College, Unpublished Phd Thesis.

Moore, D.W., White, G.M., Ross, I.J., 1984. Friction of Wheat on Corrugated Metal Surfaces. Transactions of the American Society of Agricultural Engineers, 27, pp. 1842-1847.

Myler, P., Robinson, M., 1985. Limit analysis of intersecting conical pressure vessels. International Journal of Pressure Vessels and Piping, 18, pp. 209-240.

Niloufari, A., Showkati, H., Maali, M., Mahdi Fatemi, S., 2014. Experimental investigation on the effect of geometric imperfections on the buckling and post-buckling behavior of steel tanks under hydrostatic pressure. Thin-Walled Structures, 74, pp. 59-69.

Orifici, A.C., Bisagni, C., 2013. Perturbation-based imperfection analysis for composite cylindrical shells buckling in compression. Composite Structures, 106, pp. 520-528.

Pan, B.B., Cui, W., Shen, Y.S., 2012. Experimental verification of the new ultimate strength equation of spherical pressure hulls. Marine Structures, 29, pp. 169-176.

Papadopoulos, V., Iglesis, P., 2007. The effect of non-uniformity of axial loading on the buckling behaviour of shells with random imperfections. International Journal of Solids and Structures, 44, pp. 6299-6317.

Pircher, M., Bridge, R., 2001a. The influence of circumferential weld-induced imperfections on the buckling of silos and tanks. Journal of Constructional Steel Research, 57, pp. 569-580. 
Pircher, M., Bridge, R., 1998. Effects of weld-induced circumferential imperfections on the buckling of cylindrical thin-walled shells. Transactions on Engineering Sciences, 19, pp. 112-120.

Pircher, M., Bridge, R.Q., 2001b. Buckling of thin-walled silos and tanks under axial load-some new aspects. Journal of Structural Engineering, 127, pp. 1129-1136.

Piskoty, G., Michel, S.A., Zgraggen, M., 2005. Bursting of a corn silo - An interdisciplinary failure analysis. Engineering Failure Analysis, 12, pp. 915-929.

Rejowski, K., Iwicki, P., 2016. Buckling analysis of cold formed silo column. Mechanics and Mechanical Engineering, 20, pp. 109-120.

Reuss, P., 1975. Elastic Stresses in Toriconical Pressure Vessel Heads. Periodica Polytechnica Mechanical Engineering, 19, pp. 3-10.

Ross, C.T.F., Humphries, M., 1993. The Buckling of Corrugated Circular Cylinders under Uniform External Pressure. Thin-Walled Structures, 17, pp. 259-271.

Ross, C.T.F., Little, A.P.F., 2007. Design charts for the general instability of ring-stiffened conical shells under external hydrostatic pressure. Thin-Walled Structures, 45, pp. 199-208.

Ross, C.T.F., Little, A.P.F., Adeniyi, K.A., 2005. Plastic buckling of ring-stiffened conical shells under external hydrostatic pressure. Ocean Engineering, 32, pp. 21-36.

Ross, C.T.F., Little, A.P.F., Allsop, R., Smith, C., Engelhardt, M., 2007. Plastic General Instability of Ring-Reinforced Conical Shells under External Pressure. Marine Technology, 44, pp. 268-277.

Ross, C.T.F., Whittaker, T., Little, A.P.F., 2010. Design of submarine pressure hulls to withstand buckling under external hydrostatic pressure, in: Proceedings of the International Conference on Computing in Civil and Building Engineering. pp. 2-3.

Rotter, J.M., 1986. On the Strength and Stability of Light Gauge Silos., in: Eighth International Specialty Conference on ColdFormed Steel Structures. St. Louis, Missouri, U.S.A.

Schmidt, H., 2018. Two decades of research on the stability of steel shell structures at the University of Essen (1985 - 2005): Experiments, evaluations, and impact on design standards. Advances in Structural Engineering, 21, pp. 1-29.

Schmidt, H., 2000. Stability of steel shell structures General Report. Journal of Constructional Steel Research, 55, pp. 159-181.

Schmidt, H., Krysik, R., 1991. Towards recommendations for shell stability design by means of numerically determined buckling loads. Buckling of Shell Structures, on Land, in the Sea and in the Air, London:

Schmidt, H., Swadlo, P., 1997. Strength and stability design of unstiffened cylinder/cone/cylinder and cone/cone shell assemblies under axial compression, in: Krupka, V., Schneider, P. (Eds.), Proceeding International Conference. Brno, Czech Republic, pp. 361-367.

Simitses, G.J., Shaw, D., Sheinman, I., Giri, J., 1985. Imperfection sensitivity of fiber-reinforced, composite, thin cylinders. Composites Science and Technology, 22, pp. 259-276.

Singer, J., Rosen, A., 1976. The influence of boundary conditions on the buckling of stiffened cylindrical shells, in: Buckling of Structures. Springer-Verlag, Cambridge, United State of America.

Stuhlman, C., DeLuzio, A., Almroth, B., 1966. Influence of stiffener eccentricity and end moment on stability of cylinders in compression. AIAA Journal, 4, pp. 872-877.

Tafreshi, A., 2002. Buckling and post-buckling analysis of composite cylindrical shells with cutouts subjected to internal pressure and axial compression loads. International Journal of Pressure Vessels and Piping, 79, pp. 351-359.

Taylor, T.E., Polychroni, G.Y., 1983. Optimum reinforcement of uniform thickness cone-cylinder intersections in vessels subject to internal pressure. International Journal of Pressure Vessels and Piping, 11, pp. 33-46.

Teng, J.G., 1998. Collapse Strength of Complex Metal Shell Intersections by the Effective Area Method. Journal of Pressure Vessel Technology, 120, pp. 217-222.

Teng, J.G., 1996a. Elastic buckling of cone-cylinder intersection under localized circumferential compression. Engineering Structures, 18, pp. 41-48.

Teng, J.G., 1996b. Buckling of Thin Shells: Recent Advances and Trends. Applied Mechanics Reviews, 49, pp. $263-274$. 
Teng, J.G., 1995. Cone-Cylinder Intersection under Internal Pressure: Nonsymmetric Buckling. Journal of Engineering Mechanics, 121, pp. 1298-1305.

Teng, J.G., 1994. Cone-cylinder intersection under pressure: axisymmetric failure. Journal of Engineering Mechanics, 120, pp. 1896-1912.

Teng, J.G., Barbagallo, M., 1997. Shell restraint to ring buckling at cone-cylinder intersections. Engineering Structures, 19, pp. 425-431.

Teng, J.G., Chan, F., 2001. Plastic buckling strength of T-section transition ringbeams in steel silos and tanks. Engineering Structures, 56, pp. 69-99.

Teng, J.G., Gabriel, B., 1998. Sleeved cone-cylinder intersection under internal pressure. Journal of Engineering Mechanics, 124, pp. 971-980.

Teng, J.G., Ma, H.W., 1999. Elastic buckling of ring-stiffened cone-cylinder intersections under internal pressure. International Journal of Mechanical Sciences, 41, pp. 1357-1383.

Teng, J.G., Rotter, J.M., 1992. Linear bifurcation of perfect column-supported cylinders: Support modelling and boundary conditions. Thin-Walled Structures, 14, pp. 241-263.

Teng, J.G., Rotter, J.M., 1991. Collapse behavior and strength of steel silo transition junctions. Part II: parametric study. Journal of Structural Engineering (United States), 117, pp. 3605-3622.

Teng, J.G., Zhao, Y., 2000. On the buckling failure of a pressure vessel with a conical end. Engineering Failure Analysis, 7, pp. 261-280.

Teng, J.G., Zhao, Y., Lam, L., 2001. Techniques for buckling experiments on steel silo transition junctions. Thin-Walled Structures, 39, pp. 685-707.

Tvergaard, V., Needleman, A., 2001. Effect of residual stresses on buckling localization in a cylindrical panel. AIAA Journal, 39, pp. 729-734.

Weingarten, V.I., Seide, P., Peterson, J.P., 1968. Buckling of thin-walled circular cylinders. NASA SP-8007 Monograph,.

Wenk Jr., E., Taylor, C.E., 1953. Analysis of stresses at the reinforced intersection of conical and cylindrical shells. Washington D.C, Navy Department, The David W. Taylor Model Basin.

Yao, T., He, X., Kong, F., Zhou, C.Y., 2015. Design by analysis for orthotropic pressurized structure with small end of conical shell and cylindrical shell based on Hill48 yield criterion. Thin-Walled Structures, 96, pp. 220-226.

Yu, C., Chen, Z., Wang, J., Yan, S., Yang, L., 2012. Effect of welding residual stress on plastic buckling of axially compressed cylindrical shells with patterned welds. Proceedings of the Institution of Mechanical Engineers, Part C: Journal of Mechanical Engineering Science, 226, pp. 2381-2392.

Zhao, Y., 2005. Buckling behaviour of imperfect ring-stiffened cone-cylinder intersections under internal pressure. International Journal of Pressure Vessels and Piping, 82, pp. 553-564.

Zhao, Y., Teng, J.G., 2004a. Buckling experiments on steel silo transition junctions. I: Experimental results. Journal of Constructional Steel Research, 60, pp. 1783-1801.

Zhao, Y., Teng, J.G., 2004b. Buckling experiments on steel silo transition junctions II: Finite element modeling. Journal of Constructional Steel Research, 60, pp. 1803-1823.

Zhao, Y., Teng, J.G., 2003. A stability design proposal for cone-cylinder intersections under internal pressure. International Journal of Pressure Vessels and Piping, 80, pp. 297-309.

Zhao, Y., Teng, J.G., 2001. Buckling experiments on cone-cylinder intersections under internal pressure. Journal of Engineering Mechanics, 127, pp. 1231-1239. 